\title{
BMJ Open Cohort study evaluating the burden of wounds to the UK's National Health Service in 2017/2018: update from 2012/2013
}

\author{
Julian F Guest (D , ${ }^{1}$ Graham W Fuller, ${ }^{1}$ Peter Vowden ${ }^{2}$
}

To cite: Guest JF, Fuller GW, Vowden P. Cohort study evaluating the burden of wounds to the UK's National Health Service in 2017/2018: update from 2012/2013. BMJ Open 2020;10:e045253. doi:10.1136/ bmjopen-2020-045253

- Prepublication history and supplemental materials for this paper is available online. To view these files, please visit the journal online (http://dx.doi. org/10.1136/bmjopen-2020045253).

Received 28 September 2020 Revised 19 November 2020 Accepted 23 November 2020

Check for updates

(C) Author(s) (or their employer(s)) 2020. Re-use permitted under CC BY-NC. No commercial re-use. See rights and permissions. Published by BMJ.

${ }^{1}$ Catalyst Consultants, Poole, UK ${ }^{2}$ Bradford Teaching Hospitals NHS Foundation Trust, Bradford, UK

Correspondence to Dr Julian F Guest; julian.guest@catalyst-health. com

\section{ABSTRACT}

Objective To evaluate the prevalence of wounds managed by the UK's National Health Service (NHS) in 2017/2018 and associated health outcomes, resource use and costs. Design Retrospective cohort analysis of the electronic records of patients from The Health Improvement Network (THIN) database.

Setting Primary and secondary care sectors in the UK. Participants Randomly selected cohort of 3000 patients from the THIN database who had a wound in 2017/2018. Primary and secondary outcome measures Patients' characteristics, wound-related health outcomes, healthcare resource use and total NHS cost of patient management.

Results There were an estimated 3.8 million patients with a wound managed by the NHS in 2017/2018, of which $70 \%$ healed in the study year; $89 \%$ and $49 \%$ of acute and chronic wounds healed, respectively. An estimated $59 \%$ of chronic wounds healed if there was no evidence of infection compared with $45 \%$ if there was a definite or suspected infection. Healing rate of acute wounds was unaffected by the presence of infection. Smoking status appeared to only affect the healing rate of chronic wounds. Annual levels of resource use attributable to wound management included 54.4 million district/community nurse visits, 53.6 million healthcare assistant visits and 28.1 million practice nurse visits. The annual NHS cost of wound management was $£ 8.3$ billion, of which $£ 2.7$ billion and $£ 5.6$ billion were associated with managing healed and unhealed wounds, respectively. Eighty-one per cent of the total annual NHS cost was incurred in the community. Conclusion The annual prevalence of wounds increased by $71 \%$ between $2012 / 2013$ and $2017 / 2018$. There was a substantial increase in resource use over this period and patient management cost increased by $48 \%$ in real terms. There needs to be a structural change within the NHS in order to manage the increasing demand for wound care and improve patient outcomes.

\section{INTRODUCTION}

Our 2012/2013 burden of wounds study estimated that the UK's National Health Service (NHS) managed 2.2 million patients with a wound at a cost of $£ 5.3$ billion. ${ }^{1-3}$ An estimated $61 \%$ of all wounds in that burden of wounds study healed in the study year $(79 \%$

\section{Strengths and limitations of this study}

- This is the first study to estimate how the health economic burden of wounds to the UK's National Health Service (NHS) has changed over the last 5 years.

- This study was undertaken using real-world evidence derived from the anonymised records of a randomised sample of 3000 patients in The Health Improvement Network database (a nationally representative database of clinical practice among $>11$ million patients registered with general practitioners in the UK).

- The estimates were derived following a systematic analysis of patients' characteristics, wound-related health outcomes and community-based and secondary care resource use pertaining to wound care contained in the patients' electronic records.

- The annual number of 3.8 million wounds in 2017/2018 may be an underestimate since some of the patients in our data set may have had multiple wounds, but this is not transparent in the patients' records and it is very difficult to retrospectively extricate resource use for different wounds from the records of a patient with multiple wounds of the same aetiology.

- The analysis does not consider the potential impact of those wounds that remained unhealed beyond the study period, nor the potential impact of managing patients with wounds being cared for in residential and nursing homes.

of acute wounds and $43 \%$ of chronic wounds). Patients were predominantly managed in the community with 18.6 million practice nurse visits, 10.9 million community nurse visits, 7.7 million general practitioner (GP) visits and 3.4 million hospital outpatient visits. Five years ago, patients also received 97.1 million drug prescriptions and 262.2 million dressings. Additionally, only $16 \%$ of all cases with an ulcer of the lower limb had a Doppler ankle brachial pressure index (ABPI) recorded in their records. ${ }^{1}$

This study led to such concern among politicians that the UK Parliament (House 
of Lords) debated developing a national strategy for improving the standards of wound care in the NHS. ${ }^{4}$ As a consequence, NHS England and NHS Improvement established the National Wound Care Strategy Programme in the last quarter of $2018 .{ }^{5}$ The aim of the programme is to scope the development of a national strategy for wound care in England that focuses on improving care relating to pressure ulcers, lower limb ulcers and surgical wounds. ${ }^{5}$

Between 2012 and 2017, there was an estimated 4\% decline in the number of practice nurses and a $30 \%$ decline in the number of district nurses employed in front-line patient care ${ }^{6-9}$ During this period, we reported on unwarranted variation in wound care arising in part from inconsistencies in staff involvement and dressing choice and in many instances a lack of a coherent treatment plan. ${ }^{10-16}$ Hence, it is reasonable to assume that not all patients with equal need have always had access to, or received, the same continuous levels of healthcare. However, patients should be afforded the best care available (within the context of limited resources) in order to obtain maximum health gains. ${ }^{17}$

The aim of this new study was to assess the extent of change in the burden of wounds over 5 years (ie, between $2012 / 2013$ and 2017/2018) in terms of annual prevalence, health outcomes, healthcare resource use and NHS costs.

\section{METHODS}

\section{Study design}

This was a retrospective cohort analysis of the anonymised case records of patients with a wound randomly extracted from The Health Improvement Network (THIN) database. The perspective of the analysis was the UK's NHS.

\section{The THIN database}

The THIN database contains electronic records on $>11$ million anonymised patients entered by GPs from $>560$ practices across the UK. The patient composition within the THIN database has been shown to be representative of the UK population in terms of demographics and disease distribution ${ }^{18}$ and the database theoretically contains patients' entire medical history. In particular, the database collects data on the dates that patients registered or left their practice as well as demographic data, such as date of birth and gender. Patients who reside at the same address or are members of the same family can be linked using a household identifier, provided they are registered with the same general practice.

All medical conditions and symptoms recorded electronically during a patient's consultation in the general practice are recorded in the THIN database, thereby building up long computerised medical histories using Read Codes. ${ }^{19}$ GP prescribing is computerised and entered directly into the database. Prescriptions not issued electronically (eg, during home visits) are also entered; however, there is a possibility of under-recording of such items. Information is also recorded on referrals to secondary care, including the specialty. Secondary care information and other medically-related information received by the practice are entered into the database. This includes details on hospital admissions, discharge medication, diagnosis, outpatient consultations, investigations and treatment outcomes. Details from other healthcare interventions, such as information on lifestyle and preventative healthcare, as well as a range of variables such as height, weight, body mass index, blood pressure, smoking, alcohol status, immunisation and laboratory test results are also recorded. Hence, the information contained in the THIN database reflects actual clinical practice. (THIN is a registered trademark of Cegedim SA in the UK and other countries. Reference made to the THIN database is intended to be descriptive of the data asset licensed by IQVIA, who interrogated the database and performed the randomisation independently of the authors. The authors had no direct access to the THIN database.)

\section{Study population}

The study population comprised the anonymised case records of a randomly selected cohort of 3000 patients from the THIN database (provided to the authors by IQVIA) who had a wound between 1 March 2017 and 28 February 2018.

Patients were included in the data set if they:

- Were 18 years of age or over.

- Had one of 2086 wound-related Read codes (online supplemental table S1).

- Had continuous medical history in their case record from the first mention of a wound in the study year up to the time the data were extracted from the database, unless they died, in order to exclude patients who had moved or changed their general practice.

Patients were excluded from the data set if they had a surgical wound that healed within 4 weeks of the surgical procedure (since any resource use incurred would be due to the surgical procedure and not the wound) or if they had a dermatological tumour. These inclusion/exclusion criteria are identical to those used in our earlier 2012/2013 study. ${ }^{1}$

Every patient in the THIN database who fulfilled the study's inclusion and exclusion criteria was assigned a random number by IQVIA. A representative sample was then generated by random selection of the random numbers of the whole cohort using a uniform distribution. As such, IQVIA advised that the random sample was representative of the whole population from which it was derived. The complete electronic records of the 3000 patients in the sample were then supplied to the authors, which enabled analysis of data both within and outside of the study period.

\section{Patient and public involvement}

Patients and members of the public were not directly involved in this study. The study population was limited to the anonymised records of patients in the THIN database. 


\section{Study variables and statistical analyses}

Wound type was documented in the patients' records and the authors categorised them as being either acute (ie, abscess, burn, open wound, unhealed surgical wound, trauma) or chronic (ie, diabetic foot ulcer, arterial leg ulcer, mixed leg ulcer, venous leg ulcer, unspecified leg ulcer, pressure ulcer). The following information was systematically extracted from the patients' electronic records over the 12 months from 1 March 2017 to 28 February 2018 according to the protocol approved by the ethics committee.

- Patients' characteristics.

- Patients' comorbidities (defined as a non-acute condition that patients were suffering from in the year before the start of their wound and not necessarily the year before the start of the study period).

- Wound-related healthcare resource use (which included dressings, bandages, topical treatments, negative pressure wound therapy, district nurse and healthcare assistants visits (both of whom provide care within a patient's home), practice nurse visits (who provide care within the general practice), GP visits, hospital outpatient visits, laboratory tests, prescribed medication (ie, analgesics, non-steroidal anti-inflammatory drugs (NSAIDs) and systemic antiinfectives (principally antibiotics)).

- Clinical outcomes (ie, healing and putative infection).

If a patient received a bandage or dressing on a specific date, but a clinician visit was not documented in their record, it was assumed the patient had been seen outside of the general practice by a district/community nurse or healthcare assistant. No other assumptions were made regarding missing data and there were no other interpolations.

The use of individual healthcare resources was quantified for all the patients, individually. These quantities were then used to estimate the total utilisation of each healthcare resource attributable to wound management during the study period, stratified by wound type.

Clinical outcomes and wound-related healthcare resource use associated with the sample of 3000 patients were used to model the healing rates and the total annual amounts of healthcare resource use associated with wound care provided to adult patients who were $\geq 18$ years of age by the NHS in 2017/18.

Differences between subgroups were tested for statistical significance using a $\chi^{2}$ test. Logistic regression was used to investigate relationships between baseline variables and clinical outcomes. The $p$ values $<0.05$ were considered statistically significant and have been reported. All $p$ values $\geq 0.05$ were not considered to be statistically significant and these numerical values have not been reported. All statistical analyses were performed using IBM SPSS Statistics (IBM UK, Portsmouth, Hampshire, UK).

\section{Cost of patient management}

The NHS cost of wound care for each patient was estimated by assigning unit costs at $2017 / 2018$ prices $^{20-22}$ to the quantity of healthcare resources used by individual patients from the time a patient entered the data set (ie, from 1 March 2017 or the start time of their wound if it occurred later) up to the time their wound healed or the end of the study period, whichever came first. The total cost of utilisation of each healthcare resource for the sample of 3000 patients was then combined in order to estimate their total NHS cost of wound management over the study period. The NHS cost of wound management for this cohort was then used to model the total cost of wound care provided to adult patients who were $\geq 18$ years of age by the NHS in $2017 / 2018$. The cost of wound care was also estimated by stratifying patients according to their category of wound. Accordingly, the study only considers the cost of patient management attributable to wounds in primary and secondary care settings, and does not estimate patients' overall healthcare costs.

\section{Sensitivity analyses}

Bootstrapping was undertaken to estimate the margin of error surrounding the annual prevalence of wounds and costs. This involved generating subsets of the data of each wound type on the basis of random sampling and replacing the data once sampled. These subsets enabled an estimation of the $95 \%$ confidence interval (CI) of (1) the annual number of wounds managed by the NHS in $2017 / 2018$ and (2) the NHS costs of wound management.

Deterministic sensitivity analyses were performed on all of the model's inputs to identify how the NHS cost of wound management would change by varying the different parameters in the model.

\section{RESULTS}

\section{Prevalence of wounds in the UK}

The base population of the THIN database in 2017/2018 was 2.4 million active adult patients who were $\geq 18$ years of age. The database was interrogated, independently of the authors, to identify patients with at least one of the 2086 wound-related Read codes (only 966 of the 2086 codes had been used). The search identified 174569 adult patients with a wound in $2017 / 2018$ who matched the study protocol's inclusion and exclusion criteria. The UK's population comprised 52.1 million adults who were $\geq 18$ years of age in mid-2017. ${ }^{23}$ Using these variables, the outputs of the modelling were extrapolated to the whole adult population in the UK. Accordingly, the model estimated that there were 3.8 million adult patients with a wound in the UK in 2017/2018 who matched the study protocol's inclusion and exclusion criteria, equivalent to $7 \%$ of the adult population (table 1). Bootstrapping was undertaken using 100 subsets of the counts of each wound type. This indicated the lower and upper 95\% CIs of the annual number of wounds managed by the NHS in $2017 / 2018$ to be 3.67 million and 3.96 million. Hence, the margin of error surrounding the estimated annual prevalence of wounds is around $3 \%$. 
Table 1 Annual number of adult patients with a wound and prevalence of different wound types in the UK

\begin{tabular}{lcccc}
\hline & $\begin{array}{l}\text { Annual number of } \\
\text { patients with a } \\
\text { wound in 2017/2018 }\end{array}$ & $\begin{array}{l}\text { Annual prevalence } \\
\text { among the adult UK } \\
\text { population } \\
\text { in 2017/2018 }\end{array}$ & $\begin{array}{l}\text { Annual number } \\
\text { of patients with a } \\
\text { wound in 2012/2013 }\end{array}$ & $\begin{array}{l}\text { Percentage change in the } \\
\text { annual number of patients } \\
\text { with a wound between } \\
\mathbf{2 0 1 2 / 2 0 1 3} \text { and 2017/2018 }\end{array}$ \\
\hline Abscess & $293000(8 \%)$ & 0.0056 & $160000(7 \%)$ & $83 \%$ \\
\hline Burn & $222000(6 \%)$ & 0.0043 & $87000(4 \%)$ & $155 \%$ \\
\hline Diabetic foot ulcer & $326000(9 \%)$ & 0.0063 & $169000(8 \%)$ & $93 \%$ \\
\hline Leg ulcer (arterial) & $31000(1 \%)$ & 0.0022 & $9000(<1 \%)$ & $244 \%$ \\
\hline Leg ulcer (mixed) & $102000(3 \%)$ & 0.0003 & $24000(1 \%)$ & $325 \%$ \\
\hline Leg ulcer (unspecified) & $361000(9 \%)$ & 0.0069 & $420000(19 \%)$ & $-14 \%$ \\
\hline Leg ulcer (venous) & $560000(15 \%)$ & 0.0108 & $278000(13 \%)$ & $101 \%$ \\
\hline Open wound & $337000(9 \%)$ & 0.0065 & $240000(11 \%)$ & $40 \%$ \\
\hline Pressure ulcer & $202000(5 \%)$ & 0.0039 & $153000(7 \%)$ & $32 \%$ \\
\hline Surgical wound & $519000(14 \%)$ & 0.0100 & $253000(11 \%)$ & $105 \%$ \\
\hline Trauma & $249000(7 \%)$ & 0.0048 & $158000(7 \%)$ & $58 \%$ \\
\hline Unspecified & $600000(16 \%)$ & 0.0115 & $271000(12 \%)$ & $121 \%$ \\
\hline Total & $3802000(100 \%)$ & 0.0730 & $222000(100 \%)$ & $71 \%$ \\
\hline
\end{tabular}

Percentage of total number in parentheses.

Sixteen per cent of all wounds had no diagnosis and it was not possible to infer a wound type from the patients' records. Additionally, $9 \%$ of all wounds were a leg ulcer without any further characterisation (ie, venous, arterial or mixed). Hence, the records of $25 \%$ of all wounds lacked a recorded differential diagnoses. In total, there were 1 million ulcers of the lower limb, which equates to $2.0 \%$ of the adult population having a lower limb ulcer in the study year. Of these, the number of diagnosed venous leg ulcers (560000) indicates that $1.1 \%$ of all adults $\geq 18$ years of age had such an ulcer in the study year. In addition, there were an estimated 326000 diabetic foot ulcers, which equates to $9 \%$ of all adult diabetic patients (ie, 3.46 million individuals ${ }^{24}$ ) having a foot ulcer in the study year. There were an estimated 202000 recorded pressure ulcers in the study year, equivalent to $0.4 \%$ of the total adult population (table 1 ).

\section{Patients' characteristics}

A representative sample of 3000 patients was randomly selected from the cohort of 174569 patients with a wound-related Read code by IQVIA. Patients' age in the randomly selected study population was a mean of 57.9 years and $67 \%$ were $<65$ years of age. A total of $56 \%$ of patients were female. Mean blood pressure was $130 / 77 \mathrm{mmHg}$ and patients' body mass index was a mean $29.1 \mathrm{~kg} / \mathrm{m}^{2}$. An estimated $17 \%$ of patients were smokers, $30 \%$ were ex-smokers and $52 \%$ were non-smokers. A total of $73 \%$ of patients presented with a new wound in the study year (patients' records predated the onset of the study period, enabling both pre-existing and new wounds to be identified). Table 2 (online supplemental table S2) summarises patients' characteristics according to wound type.
The percentage of patients with different comorbidities in the year before the start of their wound (and not necessarily the year before the start of the study) stratified by wound type is summarised in table 3 (online supplemental table S3). A total of $95 \%$ of patients had at least one comorbidity in the year before the start of their wound. Moreover, patients had a mean of 4.1 comorbid conditions and $57 \%$ of all patients had diabetes. It is also noteworthy that $13 \%$ of patients with a pressure ulcer were recorded as suffering from malnutrition, whereas it was $\leq 5 \%$ of patients with other wound types.

\section{Clinical outcomes}

The THIN database does not define wound healing. Wound healing was a clinical observation documented in the patient's record by their managing clinician, but not necessarily confirmed by a specialist, and it is unknown if the clinicians who managed these patients used any consistent definition. Furthermore, if a wound was not recorded as being healed it was considered to be unhealed. This assumption was supported by continued clinician visits for wound care and the continued prescribing of wound care products. On this basis, table 4 (online supplemental table S4) summarises the recorded healing rates stratified by wound type and various sub-groups between 1 March 2017 and 28 February 2018. A total of $70 \%$ of all wounds ( $\mathrm{n}=2.7$ million) healed in the study year; $89 \%$ of acute wounds healed and $49 \%$ of chronic wounds. An estimated $30 \%$ of all wounds $(\mathrm{n}=1.1$ million) remained unhealed. Patients' age did not appear to affect the overall healing rate. However, $59 \%$ of chronic wounds healed if there was no evidence of infection compared with $45 \%$ if there was a definite or suspected infection. The healing rate among acute wounds was unaffected by the presence of infection 
Table 2 Patients' baseline characteristics

\begin{tabular}{|c|c|c|c|c|c|c|c|c|c|}
\hline & $\begin{array}{l}\text { Diabetic } \\
\text { foot } \\
\text { ulcer }\end{array}$ & $\begin{array}{l}\text { Leg } \\
\text { ulcer } \\
\text { (venous) }\end{array}$ & $\begin{array}{l}\text { Open } \\
\text { wound }\end{array}$ & $\begin{array}{l}\text { Pressure } \\
\text { ulcer }\end{array}$ & $\begin{array}{l}\text { Surgical } \\
\text { wound }\end{array}$ & Unspecified & $\begin{array}{l}\text { Other } \\
\text { acute } \\
\text { wounds* }\end{array}$ & $\begin{array}{l}\text { Other } \\
\text { chronic } \\
\text { woundst }\end{array}$ & $\begin{array}{l}\text { All } \\
\text { wounds }\end{array}$ \\
\hline Mean age per patient (years) & 62.3 & 70.9 & 53.4 & 76.1 & 55.4 & 55.9 & 48.4 & 55.9 & 57.9 \\
\hline Percentage male & $51 \%$ & $48 \%$ & $40 \%$ & $40 \%$ & $42 \%$ & $49 \%$ & $40 \%$ & $42 \%$ & $44 \%$ \\
\hline Percentage smoker & $11 \%$ & $7 \%$ & $18 \%$ & $7 \%$ & $19 \%$ & $22 \%$ & $23 \%$ & $18 \%$ & $17 \%$ \\
\hline Percentage ex-smoker & $37 \%$ & $44 \%$ & $29 \%$ & $40 \%$ & $29 \%$ & $28 \%$ & $20 \%$ & $24 \%$ & $30 \%$ \\
\hline $\begin{array}{l}\text { Percentage with unknown } \\
\text { smoking status }\end{array}$ & $0 \%$ & $1 \%$ & $2 \%$ & $13 \%$ & $0 \%$ & $1 \%$ & $2 \%$ & $0 \%$ & $1 \%$ \\
\hline $\begin{array}{l}\text { Mean body mass index per } \\
\text { patient }\left(\mathrm{kg} / \mathrm{m}^{2}\right)\end{array}$ & 30.9 & 31.5 & 29.6 & 24.5 & 28.3 & 28.9 & 28.6 & 28.6 & 29.1 \\
\hline $\begin{array}{l}\text { Percentage with new } \\
\text { wounds in the study period }\end{array}$ & $61 \%$ & $59 \%$ & $87 \%$ & $80 \%$ & $77 \%$ & $80 \%$ & $81 \%$ & $62 \%$ & $73 \%$ \\
\hline
\end{tabular}

*Other acute wounds comprise abscesses, burns and traumatic wounds.

†Other chronic wounds comprise arterial, mixed and unspecified leg ulcers. Full details are available in online supplemental table S2.

( $86 \%$ vs $91 \%$ among acute wounds with no evidence of infection). An estimated $38 \%$ of chronic wounds healed if patients were smokers compared with $55 \%$ and $58 \%$ if patients were non-smokers or ex-smokers, respectively. Smoking status did not appear to affect the healing rate of acute wounds (table 4, online supplemental table S4).

For the whole cohort of patients with a wound, binary logistic regression suggested that cardiovascular disease (OR 0.57 (95\% CI 0.46 to 0.71); $<<0.001$ ), immunological disorders (OR 0.62 (95\% CI 0.45 to 0.86$) ; \mathrm{p}=0.003)$ and renal disorders (OR 0.56 (95\% CI 0.43 to 0.73 ); $\mathrm{p}<0.001$ ) were independent risk factors for non-healing during the study period. Additionally, the presence of renal disease was an independent risk factor for non-healing of diabetic foot ulcers (OR 0.28 (95\% CI 0.13 to 0.62 ); $\mathrm{p}=0.002$ ), and diabetes was an independent risk factor for non-healing of venous leg ulcers (OR 0.10 (95\% CI 0.01 to 0.96$) ; \mathrm{p}<0.02)$.

Healthcare resource use associated with patient management Patients were predominantly managed in the community by GPs, practice nurses, district/community nurses and healthcare assistants. Table 5 (online supplemental table S5) summarises the percentage of patients who utilised different resources during the study year and table 6 shows the annualised resources associated with each wound type. All the hospital admissions attributable to venous and mixed leg ulcers appeared to be linked to a suspected infection. So too were $80 \%$ of admissions attributable to diabetic foot ulcers and $95 \%$ of admissions attributable to open wounds. All these hospitalised patients with a suspected infection were prescribed antibiotics. All the hospitalised open wounds and $50 \%$ of the diabetic foot ulcers healed in the study period, but none of the venous and mixed leg ulcers healed. Less than $50 \%$ of admissions attributable to the other wound types appeared to be linked to a suspected infection and $90 \%$ of them healed during the study period. Only one-third of admissions attributable to surgical wounds and trauma appeared to be linked to a suspected infection.

Patients' treatment varied according to wound type and wound duration. Patients were prescribed a mix of dressings up to the time their wound healed or the end of the study period, whichever came first. Overall, patients' dressings were changed every 3-4 days at a nursing visit. However, this varied according to wound type. On average:

- Those patients with a burn or a venous leg ulcer had one nursing visit/dressing change every 2-3 days.

- Those patients with a diabetic foot ulcer, arterial leg ulcer, mixed leg ulcer, pressure ulcer or surgical wound had one nursing visit/dressing change every 3-4 days.

- Those patients with an unspecified leg ulcer, open wound, trauma or unspecified wound had one nursing visit/dressing change every 4-5 days.

- Those patients with an abscess had one nursing visit/ dressing change every 5-6 days.

Less than $1 \%$ of patients were prescribed the same dressing for the duration of their wound or study period. On average, patients were prescribed a mean of eight different dressing types over the study period, ranging from a mean of four different dressing types for patients with a burn to a mean of nine different dressing types for patients with an unclassified wound. In addition to dressings and bandages, varying percentages of patients were prescribed analgesics, NSAIDs and antibiotics as shown in table 5 (online supplemental table S5). 


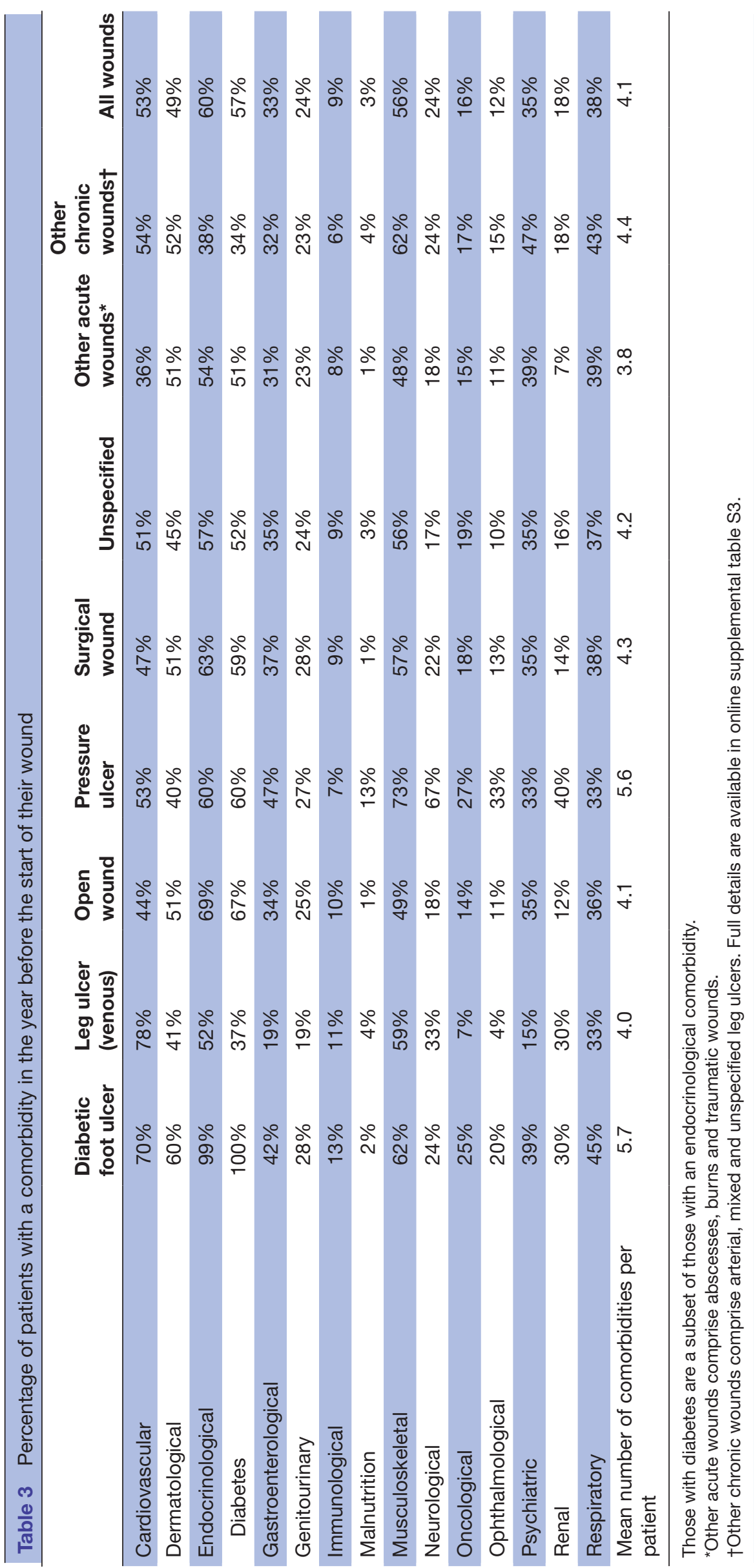


Table 4 Healing rates in the study period

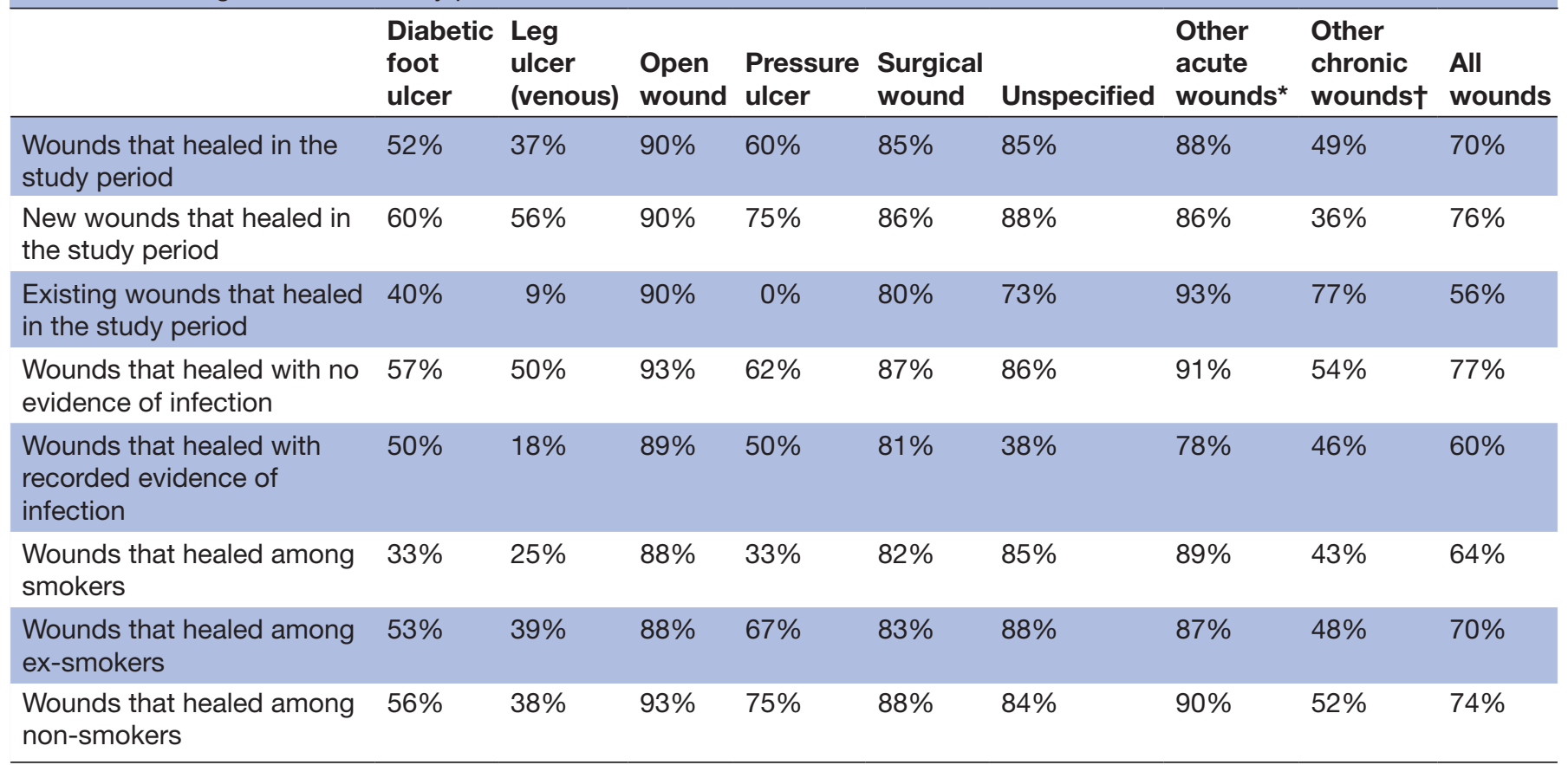

*Other acute wounds comprise abscesses, burns and traumatic wounds.

†Other chronic wounds comprise arterial, mixed and unspecified leg ulcers. Full details are available in online supplemental table S4.

Assessment of peripheral perfusion is a recognised requirement for leg ulcer and diabetic foot management. However, only $15 \%$ of all those with a leg or foot ulcer had a Doppler ABPI recorded in their records, of which $75 \%$ were prescribed some form of compression. Of the $85 \%$ who did not have their ABPI recorded, $29 \%$ were prescribed compression bandages/hosiery (table 7). Over $90 \%$ of the patients with a recorded venous leg ulcer were prescribed compression bandages/hosiery, irrespective of whether they had their ABPI recorded; so too did $>50 \%$ of patients with a recorded diabetic foot ulcer (table 7).

\section{NHS cost of patient management}

The total annual NHS cost of managing 3.8 million patients with a wound was estimated to be $£ 8.3$ billion (95\% CI £7.9 to £8.5) billion (table 8). The use of 100 bootstrapped samples indicated a $5 \%$ margin of error around the costs (table 8 ). When the bootstrapping was repeated using 1000 subsets of cost data, the margin of error decreased to $1 \%$ (ie, $95 \%$ CI $£ 8.2$ to $£ 8.4$ billion). District/community nurse visits were the primary cost driver accounting for $29 \%$ of all costs and GP office visits were the secondary cost driver accounting for a further $18 \%$ of the total cost. Healthcare assistant visits accounted for $17 \%$ of the total cost, practice nurse visits for $7 \%$ and wound care products for a further $6 \%$ (table 8 ).

Resource use associated with managing the unhealed wounds was substantially greater than that of managing the healed wounds (table 9). Consequently, the annual cost of managing the $70 \%$ of wounds that healed was estimated to be $£ 2.7$ billion compared with $£ 5.6$ billion for the $30 \%$ of wounds that did not heal within the study year. In addition, within the study period, the cost per healed wound ranged from $£ 358$ to $£ 4684$ per patient and that of an unhealed wound ranged from $£ 831$ to $£ 7886$ per patient (table 10).

Eighty-one per cent of the total annual NHS cost was incurred in the community and the remainder in secondary care. However, the distribution of costs varied according to wound type, with $68 \%$ and $85 \%$ of the total annual NHS cost of managing acute and chronic wounds, respectively, being incurred in the community and the remainder in secondary care.

\section{Sensitivity analyses}

When the healing rate of each wound type was simultaneously varied by $\pm 25 \%$, the total annual NHS cost of wound management changed by $\pm 16 \%$. When the estimated annual number of each wound type was individually changed by $\pm 25 \%$, the total annual NHS cost of wound management changed by $10 \%$ or less. When the estimated amounts of resource use were individually varied by $\pm 25 \%$, the total annual NHS cost of managing 3.8 million wounds changed by $7 \%$ or less. When the unit costs of wound care products were simultaneously varied by $\pm 25 \%$, the total annual NHS cost of managing 3.8 million patients with a wound changed by $<3 \%$.

\section{DISCUSSION}

The $2012 / 2013$ burden of wounds study ${ }^{12}$ incorporated a predictive model $^{3}$ which forecast that the prevalence of wounds would increase by $11 \%$ per annum. Thus, 
Table 5 Percentage of patients who utilised resources in the study year

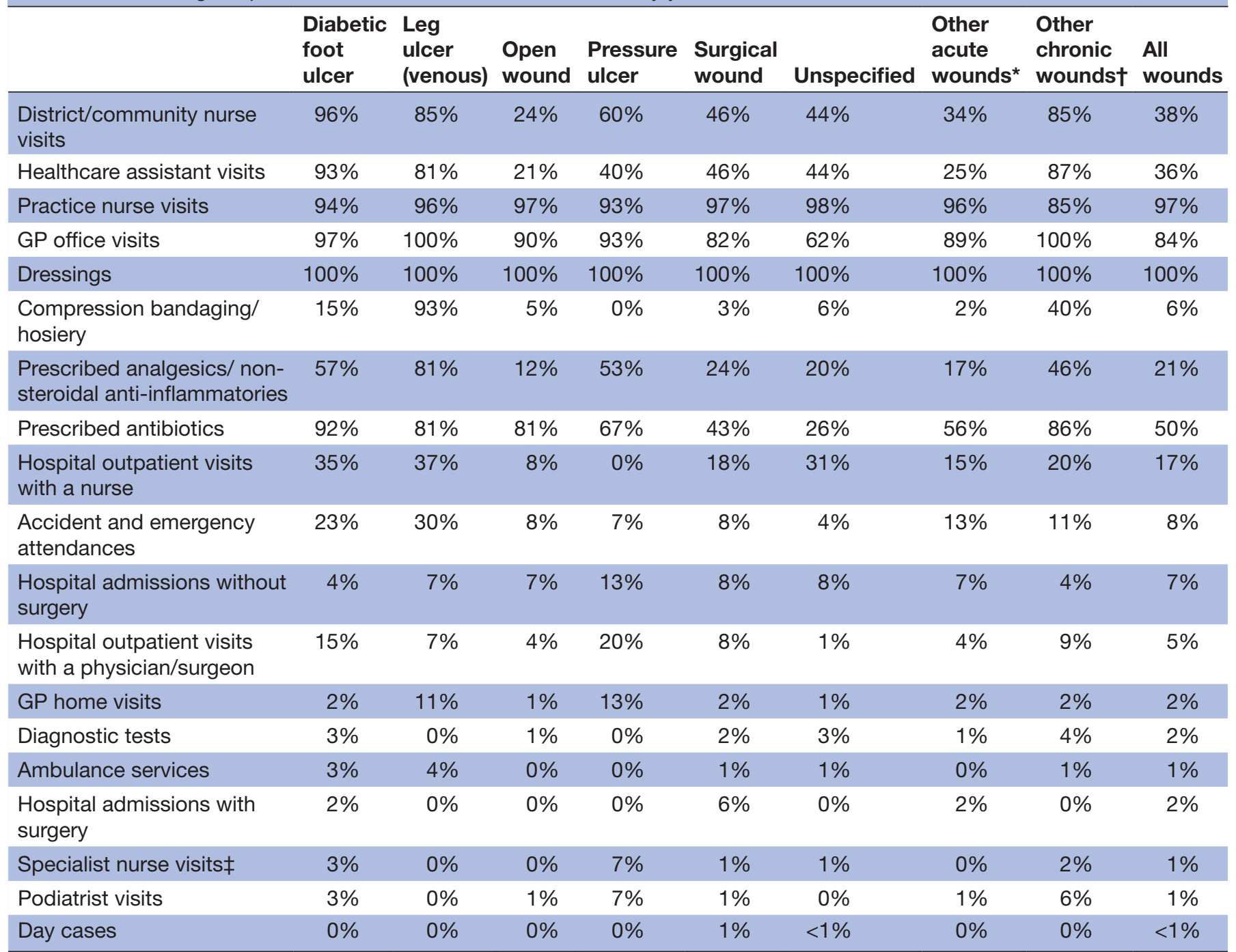

*Other acute wounds comprise abscesses, burns and traumatic wounds.

†Other chronic wounds comprise arterial, mixed and unspecified leg ulcers. Full details are available in online supplemental table S5. łIncludes tissue viability nurses and diabetic nurse specialists.

GP, general practitioner.

the model predicted there would be 3.8 million patients with a wound in $2017 / 2018$. The findings from the current analysis are consistent with the estimates from this predictive model, with the overall annual number of patients with a wound having increased by $71 \%$ over the 5 years to 3.8 million. However, the rate of increase varied according to wound type. The annual number of patients with a wound increased by $\geq 100 \%$ for many wound types, but some acute wounds increased by $\leq 83 \%$ and pressure ulcers by only $32 \%$, perhaps due in part to the ongoing pressure ulcer prevention campaign. ${ }^{25}$ The model also predicted that costs would increase in parallel with prevalence. However, when the $£ 5.3$ billion $^{1}$ was uprated to $2017 / 2018$ prices (ie, $£ 5.6$ billion), it would appear that the annual cost of wound care has increased at an approximate rate of $8 \%-9 \%$ per annum. Hence, the overall annual NHS cost of wound care has increased by $48 \%$ in real terms over the 5 years.
The aim of this study was to assess the annual health economic burden of wounds by quantifying the amount of resource use and corresponding costs associated with wound management in 2017/2018. From the NHS' perspective, resource use and corresponding cost of managing a patient with multiple wounds does not end until all the wounds heal. Some of the patients in our data set may have had multiple wounds, but this was not specifically listed within the database and was not transparent in the patients' records. Furthermore, it would be very difficult to retrospectively extricate resource use for different wounds from the records of a patient with multiple wounds of the same aetiology. Notwithstanding this, it would be unusual for an individual to have two wounds of different aetiologies at the same time. However, it may be that in $2017 / 2018$, some of the patients with an ulcer of the lower limb had a second ulcer, although it would be unlikely that patients with other wounds would 


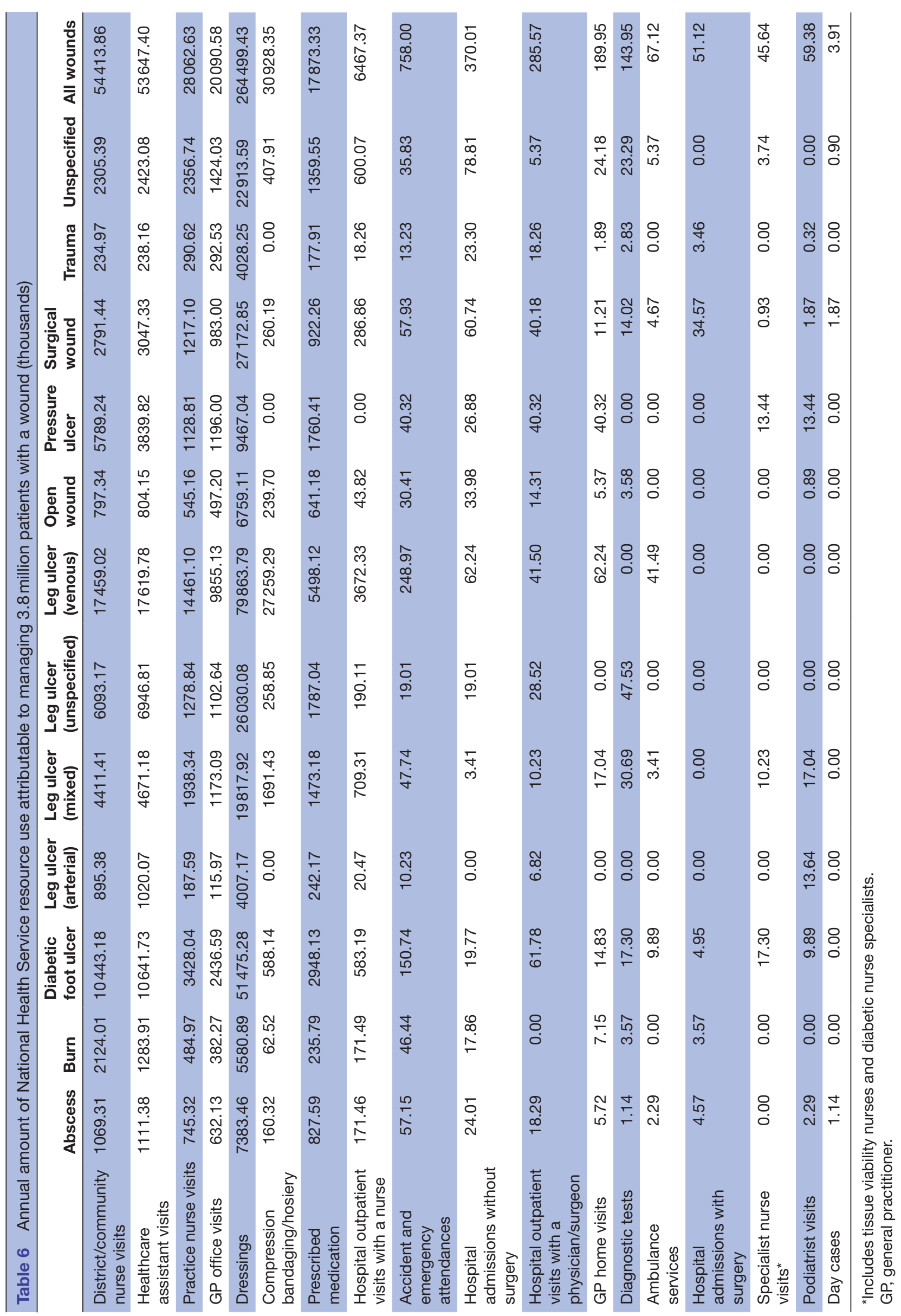


Table 7 Use of Doppler in patients with an ulcer of the lower limb to measure ankle brachial pressure index

\begin{tabular}{lllc}
\hline & $\begin{array}{l}\text { Percentage } \\
\text { who had a } \\
\text { recorded } \\
\text { Doppler }\end{array}$ & $\begin{array}{l}\text { Percentage } \\
\text { who did } \\
\text { not have a } \\
\text { recorded } \\
\text { Doppler }\end{array}$ & $\begin{array}{l}\text { Percentage of } \\
\text { these who were } \\
\text { prescribed a } \\
\text { compression } \\
\text { bandage/hosiery }\end{array}$ \\
\hline $\begin{array}{l}\text { Ulcer type } \\
\text { Venous leg }\end{array}$ & $59 \%$ & $41 \%$ & $88 \%$ \\
ulcer & & & $99 \%$ \\
\hline $\begin{array}{l}\text { Arterial leg } \\
\text { ulcer }\end{array}$ & $22 \%$ & $78 \%$ & $0 \%$ \\
Mixed leg & $27 \%$ & $73 \%$ & $100 \%$ \\
ulcer & & & $0 \%$ \\
\hline $\begin{array}{l}\text { Unspecified } \\
\text { leg ulcer }\end{array}$ & $0 \%$ & $100 \%$ & $26 \%$ \\
\hline $\begin{array}{l}\text { Diabetic } \\
\text { foot ulcer }\end{array}$ & $8 \%$ & & $50 \%$ \\
\hline $\begin{array}{l}\text { All lower } \\
\text { limb ulcers }\end{array}$ & $15 \%$ & $92 \%$ & $12 \%$ \\
\hline
\end{tabular}

have multiple wounds. If $10 \%$ of patients with an ulcer of the lower limb had a second ulcer, the total number of wounds would increase by $5 \%$ from 3.8 million to 4.0 million. The implication of this is that the NHS may have managed more than 3.8 million wounds in 2017/2018. Nevertheless, the estimated amount of resource use and corresponding costs as presented would remain unchanged since all the resources and wound care products used in managing each patient were documented in their record (despite the lack of granularity surrounding the number of wounds they may have had).

Another study limitation was the exclusion of a wound if it recurred after having healed during the study period. If $10 \%$ of the diabetic foot ulcers, venous leg ulcers and pressure ulcers and $5 \%$ of the other leg ulcers recurred after healing in the study period, it would imply that 3.8 million patients had 3.97 million wounds in 2017/2018. If these wounds recurred, on average, at the 6 months mid-point, the annual NHS cost of wound care could be potentially $2 \%$ higher than estimated at $£ 8.5$ billion.

In the 2012/2013 data set, $65 \%$ of all the patients with a wound were 65 years of age or older. ${ }^{2}$ However, in the $2017 / 2018$ data set, only $33 \%$ of patients were 65 years of age or older. This was a significant difference $(\mathrm{p}<0.001)$, suggesting that wounds are no longer predominantly the preserve of the elderly. In $2012 / 2013,39 \%$ of all patients were non-smokers. However, by 2017/2018, this percentage had increased significantly to $52 \%$ $(p<0.001)$. In parallel with these changes in the patient demographics, there was a change in the distribution of comorbidities. In particular, in 2012/2013, $73 \%$ and $37 \%$ of patients had cardiovascular and musculoskeletal disorders, but in 2017/2018 an estimated 53\% ( $<<0.001)$ and $56 \%(\mathrm{p}<0.02)$ had cardiovascular and musculoskeletal disorders, respectively. Most striking, however, was that $29 \%$ of the $2012 / 2013$ cohort had diabetes compared with $57 \%$ in $2017 / 18(\mathrm{p}<0.05)$. Additionally, the variation in the mean number of comorbidities associated with different wound types in this study parallels the variation in Charlson Comorbidity Index associated with different wound types observed in a patient population in Asia. ${ }^{26}$

Over the 5-year period, the healing rate of acute wounds increased by a mean of $13 \%$ and that of chronic wounds by a mean of $14 \%$. However, within this estimate, the healing rate of diabetic foot ulcers and pressure ulcers increased by $27 \%$ and $43 \%$, respectively, but the healing rate of venous and mixed leg ulcers decreased by $21 \%$ and $29 \%$, respectively. The percentage of patients accessing different resources increased over the 5 years and so too did the absolute amount of resource use. For example, between 2012/2013 and 2017/2018, there was $>10000 \%$ increase in the number of healthcare assistant visits (from 0.5 million to 53.6 million), a $399 \%$ increase in the number of district/community nurse visits (from 10.9 million to 54.4 million), $164 \%$ increase in the number of GP visits (from 7.7 million to 20.3 million), $100 \%$ increase in the number of hospital outpatient visits (from 3.4 million to 6.8 million) and $51 \%$ increase in the number of practice nurse visits (from 18.6 million to 28.1 million). In addition, there was a $2 \%$ decrease in the number of specialist nurse visits and a $104 \%$ increase in the amount of wound care products used. The changes in the annual cost of these resources mirror the changes in utilisation of these resources. Accordingly, the NHS cost of wound care in $2017 / 2018$ was an estimated $£ 8.3$ billion, which is approaching the combined annual NHS cost of managing osteo and rheumatoid arthritis, which was reported to be $£ 10.2$ billion in 2017 . $^{27}$

The shift towards greater utilisation of community-based resources is reflected in the distribution of care between secondary care and the community. In 2012/2013, 48\% of the costs of managing acute wounds and $78 \%$ of the costs of managing chronic wounds were incurred in the community and the remainder in secondary care. ${ }^{12}$ In $2017 / 2018,68 \%$ and $85 \%$ of the costs of managing acute and chronic wounds, respectively, were incurred in the community and the remainder in secondary care.

This present study has also highlighted that resource use associated with managing the $30 \%$ of wounds that did not heal in the study year was substantially greater than that of managing the $70 \%$ of wounds that did heal within the study year (eg, 325\% more hospital outpatient visits, $178 \%$ more practice nurse visits, $171 \%$ more GP visits, $118 \%$ more accident and emergency attendances, $97 \%$ more district/community nurse visits and $85 \%$ more healthcare assistant visits). Consequently, the annual cost of managing wounds that healed within the study year was estimated to be $£ 2.7$ billion compared with $£ 5.6$ billion for the $30 \%$ of wounds that did not heal within the study year. In addition, the mean cost of an unhealed wound ( $£ 3700$ ) was approximately 2.5 times more than that of a wound that healed during the study period (£1500). Sensitivity 


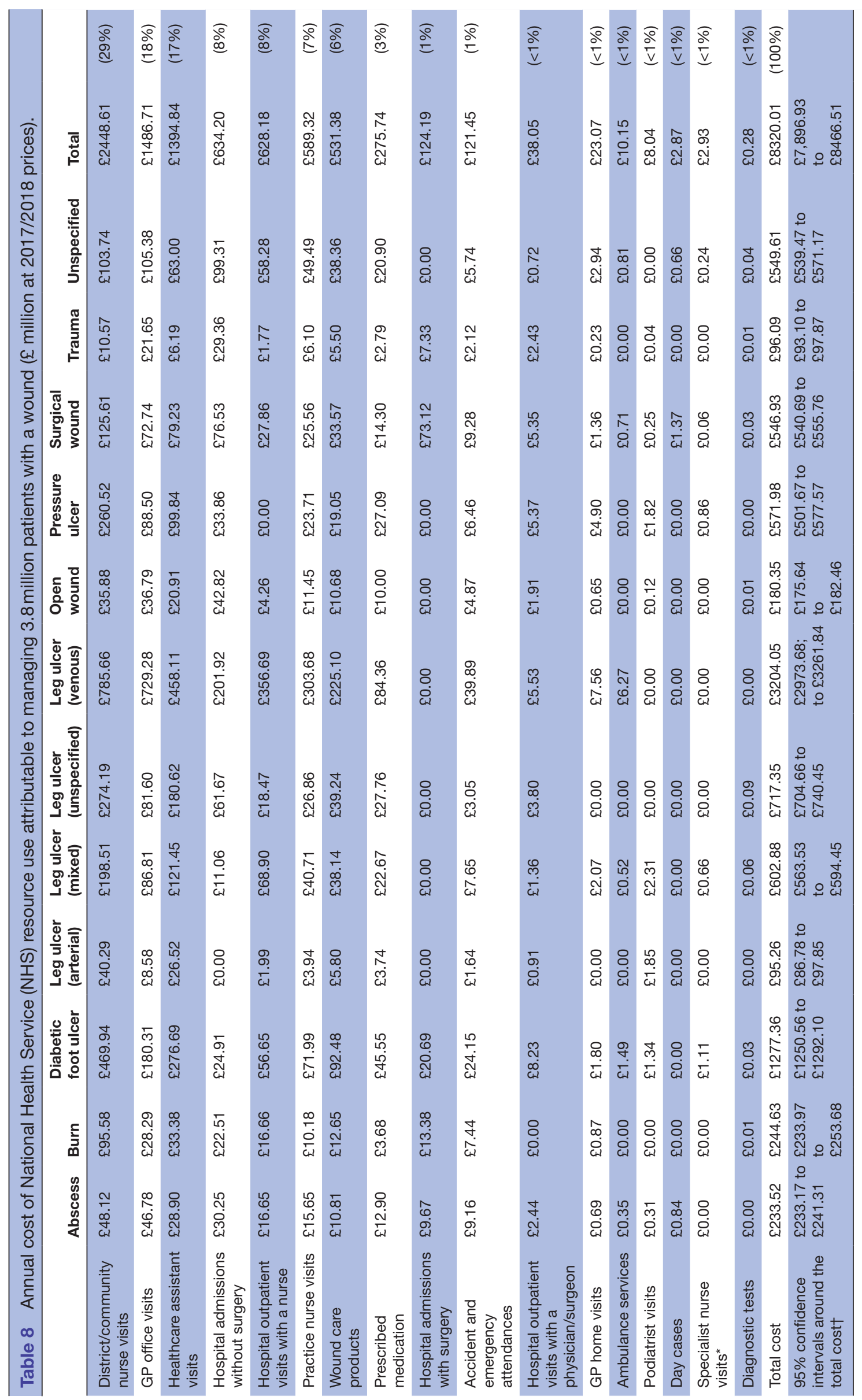


Table 9 Annual amount and corresponding cost (at 2017/2018 prices) of National Health Service (NHS) resource use attributable to managing 3.8 million patients with a wound, stratified by healing

\begin{tabular}{|c|c|c|c|c|c|c|}
\hline & \multicolumn{2}{|c|}{$\begin{array}{l}\text { Annual number } \\
\text { (thousand) }\end{array}$} & \multirow[b]{2}{*}{$\begin{array}{l}\text { Percentage } \\
\text { difference in } \\
\text { resource use } \\
(\%)\end{array}$} & \multicolumn{2}{|l|}{$\begin{array}{l}\text { Annual cost } \\
\text { (£ million) }\end{array}$} & \multirow[b]{2}{*}{$\begin{array}{l}\text { Percentage } \\
\text { difference in } \\
\text { resource cost } \\
(\%)\end{array}$} \\
\hline & Healed & Unhealed & & Healed & Unhealed & \\
\hline Number of patients with a wound & 2677.00 & 1125.00 & & & & \\
\hline Ambulance services & 4.51 & 62.61 & $1288 \%$ & $£ 0.68$ & $£ 9.47$ & $1293 \%$ \\
\hline Hospital outpatient visits & 1286.85 & 5466.09 & $325 \%$ & $£ 130.85$ & $£ 535.38$ & $309 \%$ \\
\hline Practice nurse visits & 7430.80 & 20631.83 & $178 \%$ & $£ 156.05$ & $£ 433.27$ & $178 \%$ \\
\hline GP visits & 5460.16 & 14820.37 & $171 \%$ & $£ 407.22$ & $£ 1102.56$ & $171 \%$ \\
\hline Podiatrist visits & 16.11 & 43.27 & $169 \%$ & $£ 2.18$ & $£ 5.86$ & $169 \%$ \\
\hline Prescribed medication & 5593.33 & 12280.00 & $120 \%$ & $£ 86.72$ & $£ 189.02$ & $118 \%$ \\
\hline $\begin{array}{l}\text { Accident and emergency } \\
\text { attendances }\end{array}$ & 238.34 & 519.66 & $118 \%$ & $£ 38.19$ & $£ 83.26$ & $118 \%$ \\
\hline District/community nurse visits & 18342.87 & 36070.99 & $97 \%$ & $£ 825.59$ & $£ 1623.02$ & $97 \%$ \\
\hline $\begin{array}{l}\text { Wound care products (dressings/ } \\
\text { bandages/hosiery/creams/ointments/ } \\
\text { tapes, etc) }\end{array}$ & & & & $£ 181.06$ & $£ 350.32$ & $93 \%$ \\
\hline Healthcare assistant visits & 18816.65 & 34830.75 & $85 \%$ & $£ 489.23$ & $£ 905.61$ & $85 \%$ \\
\hline Specialist nurse visits* & 21.12 & 24.52 & $16 \%$ & $£ 1.35$ & $£ 1.58$ & $17 \%$ \\
\hline Hospital admissions and day cases & 286.73 & 138.31 & $-52 \%$ & $£ 427.89$ & $£ 333.37$ & $-22 \%$ \\
\hline Diagnostic tests & 86.89 & 57.06 & $-34 \%$ & $£ 0.19$ & $£ 0.09$ & $-53 \%$ \\
\hline Total & & & & $£ 2747.20$ & $£ 5572.81$ & $103 \%$ \\
\hline
\end{tabular}

*Includes tissue viability nurses and diabetic nurse specialists.

GP, general practitioner.

analysis showed the healing rate to have a large effect on the cost of wound care and regression analysis indicated that the presence of cardiovascular disease or immunological disorders or renal disorders were all independent risk factors for non-healing during the study period. In the 2012/2013 study both nutritional deficiency and diabetes were independent risk factors for non-healing during the study period. ${ }^{1}$ In this study, only a mean of

Table 10 Total annual National Health Service (NHS) cost (at 2017/2018 prices) of wound care attributable to managing 3.8 million patients with a wound and cost per patient, stratified by healing

\begin{tabular}{lcclll}
\hline & \multicolumn{2}{c}{ Total NHS cost for all patients (£ million) } & & \multicolumn{2}{c}{ Mean annual NHS cost per patient } \\
\cline { 2 - 3 } \cline { 5 - 5 } & Healed wounds & Unhealed wounds & & Healed wounds & Unhealed wound \\
\hline Abscess & 152.12 & 81.40 & 104.40 & $£ 604.88$ & $£ 1977.94$ \\
Burn & 140.23 & 787.25 & $£ 754.81$ & $£ 2922.16$ \\
Diabetic foot ulcer & 490.11 & 41.56 & $£ 2874.36$ & $£ 5056.71$ \\
Leg ulcer (arterial) & 53.70 & 459.11 & $£ 4684.83$ & $£ 4061.31$ \\
Leg ulcer (mixed) & 143.77 & 337.77 & $£ 1901.79$ & $£ 6411.01$ \\
Leg ulcer (unspecified) & 379.58 & 2781.49 & $£ 2036.67$ & $£ 7886.98$ \\
Leg ulcer (venous) & 422.56 & 52.84 & $£ 421.83$ & $£ 1515.03$ \\
Open wound & 127.51 & 481.54 & $£ 747.75$ & $£ 5972.28$ \\
Pressure ulcer & 90.44 & 157.01 & $£ 884.11$ & $£ 2024.49$ \\
Surgical wound & 389.92 & 12.31 & $£ 358.09$ & $£ 831.63$ \\
Trauma & 83.78 & 276.13 & $£ 533.82$ & $£ 3146.03$ \\
Unspecified & 273.48 & & &
\end{tabular}


$3 \%$ of patients had malnutrition, possibly reflecting the significantly lower age of the study population. However, $13 \%$ of patients with a pressure ulcer had malnutrition and their BMI was a mean of $24.5 \mathrm{~kg} / \mathrm{m}^{2}$ which was lower than that of patients with other wound types. Diabetes was not found to exert an independent effect on healing possibly because $59 \%$ of the patients with diabetes also had cardiovascular disease, $19 \%$ had renal disease, and $11 \%$ had immunological disorders. In addition, $61 \%$ of the patients with diabetes had musculoskeletal disorders and $38 \%$ had a mental health condition (principally depression and anxiety). The age of the patients with diabetes was a mean of 59.2 years per patient and $44 \%$ were male.

This and many other studies ${ }^{10-12} 2829$ have shown that wound management is predominantly a nurse-led discipline. Nevertheless, there still seems to be minimal clinical involvement of tissue viability nurses and other specialist nurses in direct patient management. In addition, dressing and bandage types were continually switched at successive wound dressing changes for the majority of patients, suggesting confusion and conflict within the treatment plan. It was not possible to determine which professional groups were the decision makers in relation to changes in dressing type and what the goal of treatment changes were as this information was not specifically recorded in the patients' records. Moreover, an estimated $25 \%$ of all wounds being managed within the NHS in 2017/2018 lacked a recorded differential diagnosis in the patient's record. Furthermore, only $15 \%$ of patients with an ulcer on the lower limb had a vascular assessment with Doppler ABPI recorded in their records, contrary to national guidance. ${ }^{30} 31$ Nevertheless, we observed a $14 \%$ decrease in the proportion of patients with unspecified leg ulcers since 2015 which may be due to an increase in measuring ABPI even if it was not documented in the patients' records. It remains unclear and disappointing to find that records still lacked documentation of this essential investigation. Moreover, 5 years later, patients' records still appear to lack any evidence of consistent reporting of wound management processes. This may be indicative of the difficulties experienced by non-specialist healthcare professionals in the community with establishing a working diagnosis.

It seems unclear how the NHS can best respond to the ever-increasing demand for wound care. The NHS Long Term Plan ${ }^{32}$ has described how the NHS will move to a new service model in which patients will have properly joined-up care at the right time in the optimal care setting. This will involve having online 'digital' GP consultations, and redesigned hospital support in order to free-up about one-third of outpatient appointments. ${ }^{32}$ Additionally, GP practices will be funded to create integrated teams of GPs, community health and social care staff. ${ }^{32}$ These expanded community health teams will provide fast support to people in their own homes. ${ }^{32}$ Ultimately, the NHS will aim to create Integrated Care Systems everywhere by April 2021, which bring together local organisations to deliver a 'triple integration' of primary and specialist care, physical and mental health services and health with social care. ${ }^{32}$ Additionally, commissioners will be tasked to share decisions with providers on population health, service redesign and long term plan implementation. ${ }^{32}$ Such a change in the system may facilitate getting the optimum care to patients at the right time in the right setting in order to improve the patient experience and health outcomes, thereby freeing-up healthcare resources and reducing costs. However, will this method of care delivery improve wound care and associated patient outcomes? The introduction of truly seamless care with integrated electronic patient records would improve overall patient management. However, patients with wounds need faceto-face interaction with clinicians on a regular basis to monitor progress and have their dressings changed. The authors are therefore of the opinion that this model would require the NHS to establish dedicated wound care clinics in the community at which patients receive consistent and integrated care from clinicians with qualified experience in wound care, with the clinics linking directly to electronic patient records which are integrated across all healthcare sectors. These clinics could provide both direct care and holistic assessments of patients allowing coordinated management of any comorbidities which may impact on wound healing

The advantages and disadvantages of using the THIN database for this study have been previously discussed. ${ }^{1}$ In summary, the advantage of using the THIN database is that the patient pathways and associated resource use are based on real-world evidence derived from clinical practice. However, the possibility of resource use associated with managing a comorbidity being conflated with that of wound management cannot be excluded. While the study results are compelling, the analyses were based on clinicians' entries into their patients' records and inevitably subject to a certain amount of imprecision and lack of detail. Moreover, the computerised information in the THIN database is collected by GPs for clinical care purposes and not for research. Prescriptions issued by GPs and practice nurses are recorded in the database, but it does not specify whether the prescriptions were dispensed or detail patient compliance with the product. Despite these limitations, it is the authors' opinion that the THIN database affords one of the best sources of real-world evidence for clinical practice in the UK, since it is representative of the whole UK population ${ }^{18} 33$ and there are only minor differences between this and other real-world evidence databases in the UK ${ }^{33}$ Moreover, the changes between 2012/2013 and 2017/2018 are clinically relevant, since the sample size in this study was 3000 patients versus 1000 patients in the earlier study. Furthermore, a review of Medline in August 2020 identified 283 articles in peer-reviewed journals in which the THIN database had been used to characterise clinical practice in a wide range of therapeutic areas in the UK, of which 28 had been published in BMJ Open since 2014. Notwithstanding this, it is not possible to ascertain from the data 
set whether some of the changes between 2012/2013 and $2017 / 2018$ are due to increased complexity of wound aetiology and a decrease in competency of the clinical staff caring for these patients. There is no recognised complexity index/score for wounds so any measure of this would be subjective. Additionally, the low involvement of senior staff in patient management may indicate competency as a possible issue, but this cannot be quantified.

The analysis does not consider the potential impact of those wounds that remained unhealed beyond the study period. The THIN database may have under-recorded use of some healthcare resources outside the GP's surgery if not documented in the GP records, and the impact of this was addressed in sensitivity analyses. In particular, not all community records may have been linked to the GP records. The analysis excluded hospital-based prescribing, but this should have minimal impact on the results as most prescribing is undertaken by GPs and nurses in the community. Also excluded is the potential impact of managing patients with wounds being cared for in residential and nursing homes.

The analysis only considered the annual cost of NHS resource use for the 'average adult patient', and no attempt was made to stratify resource use and costs according to gender, comorbidities, wound size, wound severity and other disease-related factors. Also excluded were the costs incurred by patients and indirect societal costs as a result of patients taking time off work. In $2012 / 2013$, only $35 \%$ of patients with a wound were of working age. However, in $2017 / 2018$ nearly $70 \%$ of the cohort was less than 65 years of age and $6 \%$ of patients in this age group were admitted into hospital. In April 2018, the gross median salary for full-time employees was $£ 569$ per week. ${ }^{34}$ Hence, the indirect societal cost in lost gross domstic product (GDP) arising from hospitalisation (assuming $96 \%$ of these patients were in full-time employment $^{35}$ ) amounted to $£ 87$ million. This is likely to be an underestimate, since a proportion of patients are likely to be absent from work due to their wound, but residing in their home. Nevertheless, this is a relatively negligible indirect cost considering that nocturia (which predominantly affects the elderly population) accounts for over $£ 4$ billion in lost GDP. ${ }^{36}$

Notwithstanding the study's limitations, real-world evidence highlights the substantial burden that wounds continue to impose on the NHS in an average year. Clinical and economic benefits to both patients and the NHS could accrue from strategies that focus on (1) accurate diagnosis, (2) preventing infection and (3) improving wound-healing rates. However, these benefits are unlikely to be realised unless there is a structural change within the NHS in order to manage the increasing demand for wound care.

Acknowledgements The authors thank Kathryn Vowden, University of Bradford, Bradford, UK, for her appraisal and input into this manuscript.

Contributors JFG designed the study, obtained the THIN data set, managed the analyses, performed some analyses, checked all the other analyses, and wrote the manuscript. GWF conducted much of the analyses. PV scrutinised the analyses, suggested further analyses and helped interpret some of the findings. All the authors were involved in revising the manuscript and gave final approval. JFG is the guarantor of this work and, as such, had full access to all the data in the study and takes responsibility for the integrity of the data and the accuracy of the data analysis.

Funding This study was funded by JFG, the lead author and by a donation from Essity, Hull, UK.

Competing interests None declared.

Patient consent for publication Not required.

Ethics approval Ethics approval to use anonymised patients' records from the THIN database for this study was obtained from the Research Ethics Committee that appraises studies using the THIN database (Reference number 18THIN093).

Provenance and peer review Not commissioned; externally peer reviewed.

Data availability statement Data are available upon reasonable request. All data relevant to the study are included in the article or uploaded as supplemental information. The THIN data set cannot be shared as this restriction was a condition of the ethics approval obtained from the Research Ethics Committee (Reference number 18THIN093). Questions concerning the data underlying the results can be sent to the corresponding author.

Supplemental material This content has been supplied by the author(s). It has not been vetted by BMJ Publishing Group Limited (BMJ) and may not have been peer-reviewed. Any opinions or recommendations discussed are solely those of the author(s) and are not endorsed by BMJ. BMJ disclaims all liability and responsibility arising from any reliance placed on the content. Where the content includes any translated material, BMJ does not warrant the accuracy and reliability of the translations (including but not limited to local regulations, clinical guidelines, terminology, drug names and drug dosages), and is not responsible for any error and/or omissions arising from translation and adaptation or otherwise.

Open access This is an open access article distributed in accordance with the Creative Commons Attribution Non Commercial (CC BY-NC 4.0) license, which permits others to distribute, remix, adapt, build upon this work non-commercially, and license their derivative works on different terms, provided the original work is properly cited, appropriate credit is given, any changes made indicated, and the use is non-commercial. See: http://creativecommons.org/licenses/by-nc/4.0/.

ORCID iD

Julian F Guest http://orcid.org/0000-0003-0162-2007

\section{REFERENCES}

1 Guest JF, Ayoub N, Mcllwraith T, et al. Health economic burden that wounds impose on the National health service in the UK. BMJ Open 2015;5:e009283.

2 Guest JF, Ayoub N, Mcllwraith T, et al. Health economic burden that different wound types impose on the UK's National Health Service. Int Wound J 2017;14:322-30.

3 Guest JF, Vowden K, Vowden P. The health economic burden that acute and chronic wounds impose on an average clinical commissioning group/health board in the UK. J Wound Care 2017;26:292-303.

4 House of Lords Hansard. House of Lords debate on developing a strategy for improving the standards of wound care in the NHS, 2017. Available: https://hansard.parliament.uk/lords/201711-22/debates/6C57E65A-A04D-449B-82E9-C836F088A696/ NHSWoundCare

5 NHS England. National wound care strategy programme. Available: https://www.ahsnnetwork.com/about-academic-health-sciencenetworks/national-programmes-priorities/national-wound-carestrategy-programme

6 NHS Digital. General practice provisional tables december 2017nurse, 2018. Available: https://digital.nhs.uk/data-and-information/ publications/statistical/general-and-personal-medical-services/as-at31-december-2017-provisional-experimental-statistics

7 NHS Digital. NHS-staf-sept-2016-summ, 2017. Available: https:// digital.nhs.uk/data-and-information/publications/statistical/nhsworkforce-statistics/nhs-workforce-statistics-november-2016provisional-statistics

8 House of Commons Health Committee. The nursing workforce Second Report of Session 2017-19: HC353, 2018. Available: https:// 
publications.parliament.uk/pa/cm201719/cmselect/cmhealth/353/ 353.pdf

9 Royal College of Nursing. The UK nursing labour market review 2018, 2018. Available: https://www.ren.org.uk

10 Guest JF, Fuller GW, Vowden P. Clinical outcomes and costeffectiveness of three different compression systems in newly-diagnosed venous leg ulcers in the UK. J Wound Care 2017;26:244-54.

11 Guest JF, Singh H, Rana K, et al. Cost-effectiveness of an electroceutical device in treating non-healing venous leg ulcers: results of an RCT. J Wound Care 2018;27:230-43.

12 Panca M, Cutting K, Guest JF. Clinical and cost-effectiveness of absorbent dressings in the treatment of highly exuding VLUs. $J$ Wound Care 2013;22:109-18.

13 Guest JF, Fuller GW, Vowden P. Diabetic foot ulcer management in clinical practice in the UK: costs and outcomes. Int Wound $J$ 2018;15:43-52.

14 Guest JF, Fuller GW, Vowden P. Venous leg ulcer management in clinical practice in the UK: costs and outcomes. Int Wound $J$ 2018;15:29-37.

15 Guest JF, Fuller GW, Vowden P, et al. Cohort study evaluating pressure ulcer management in clinical practice in the UK following initial presentation in the community: costs and outcomes. BMJ Open 2018;8:e021769.

16 Guest JF, Fuller GW, Vowden P. Costs and outcomes in evaluating management of unhealed surgical wounds in the community in clinical practice in the UK: a cohort study. BMJ Open 2018;8:e022591.

17 Alderwick H, Robertson R, Appleby J, et al. Better value in the NHS. The role of changes in clinical practice, 2015. Available: www. kingsfund.org.uk

18 Blak BT, Thompson M, Dattani H, et al. Generalisability of the health improvement network (thin) database: demographics, chronic disease prevalence and mortality rates. Inform Prim Care 2011;19:251-5

19 NHS Digital. Read codes, 2018. Available: https://digital.nhs.uk/ article/1104/Read-Codes [Accessed 10 Mar 2018]

20 Curtis L, Burns A. Unit costs of health and social care 2019. University of Kent, personal social services research unit, Canterbury, 2019. Available: https://www.pssru.ac.uk/project-pages/unit-costs/ unit-costs-2019/ [Accessed 1 Jul 2020].

21 Department of Health. National schedule of NHS reference costs 2018/19. Available: https://improvement.nhs.Uk/resources/referencecosts [Accessed 1 Jul 2020].
22 Drug Tariff, 2019. Available: https://www.drugtariff.co.uk [Accessed 1 Jul 2020].

23 Office for National Statistics, 2017. Available: https://www.ons. gov.uk/peoplepopulationandcommunity/populationandmigration/ populationestimates/datasets/populationestimatesforukenglanda ndwalesscotlandandnorthernireland

24 Diabetes UK. Facts and figures, 2019. Available: https://www. diabetes.org.uk/professionals/position-statements-reports/statistics

25 React to Red Skin. Available: http://www.reacttoredskin.co.uk/

26 Lo ZJ, Lim X, Eng D, et al. Clinical and economic burden of wound care in the tropics: a 5-year institutional population health review. Int Wound J 2020;17:790-803.

27 Arthritis Research UK. The Nation's Joint Problem, 2017. Available: https://www.arthritiscare.org.uk

28 Guest JF, Taylor RR, Vowden K, et al. Relative cost-effectiveness of a skin protectant in managing venous leg ulcers in the UK. J Wound Care 2012;21:389-98.

29 Guest JF, Ayoub N, Greaves T. Clinical outcomes and costeffectiveness of an externally applied electroceutical device in managing venous leg ulcers in clinical practice in the UK. $J$ Wound Care 2015;24:572-80.

30 Scottish Intercollegiate Guidelines Network. SIGN guideline 120: management of chronic venous leg ulcers. 2010, 2010. Available: http://sign.ac.uk/pdf/sign120.pdf

31 National Institute for Health and Care Excellence (NICE). Diabetic foot problems: prevention and management. NICE guidelines [NG19], 2015. Available: https:// nice.org.uk/guidance/ng19 [Accessed 30 Nov 2016].

32 NHS England. The NHS long term plan, 2019. Available: https://www. longtermplan.nhs.uk/

33 Kneale D, Khatwa M, Thomas J. Identifying and appraising promising sources of UK clinical health and social care data for use by NICE, 2016. Available: https://eppi.ioe.ac.uk/cms/Default.aspx? tabid $=3673$

34 Office for National Statistics. Employee earnings in the UK: 2018 , 2018. Available: https://www.ons.gov.uk/employmentandlabourm arket/peopleinwork/earningsandworkinghours/bulletins/annualsurvey ofhoursandearnings/2018

35 Office for National Statistics. Unemployment, 2018. Available: https:// www.ons.gov.uk/employmentandlabourmarket/peoplenotinwork/ unemployment

36 Weidlich D, Andersson FL, Oelke M, et al. Annual direct and indirect costs attributable to nocturia in Germany, Sweden, and the UK. Eur J Health Econ 2017;18:761-71. 